\title{
Bingöl ili Merkez İlçesi Yelesen ve Dikme Köyleri Meralarının Farklı Yöney ve Yükseltilerinde Yer Alan Bitki Türleri
}

\author{
Erdal ÇAÇAN ${ }^{1 *}$, Mehmet BAŞBAĞ ${ }^{2}$ \\ ${ }^{1}$ Bingöl Üniversitesi Genç Meslek Yüksekokulu, Bitkisel ve Hayvansal Üretim Bölümü, Bingöl, Türkiye. \\ ${ }^{2}$ Dicle Üniversitesi Ziraat Fakültesi, Tarla Bitkileri Bölümü, Diyarbakır, Türkiye. \\ *Sorumlu yazar: erdalcacan@gmail.com
}

\begin{abstract}
Öz
Bu araştırma; Bingöl ili merkez ilçesi Yelesen ve Dikme köyleri meralarının farklı yöney ve yükseltilerinde yer alan bitki türlerinin tespiti ve birbirleriyle karşılaştırılması amacıyla 2012 ve 2013 yıllarında yürütülmüştür. íki yıllık araştırmanın sonucunda; toplam 29 bitki familyasının, 96 farklı cinsinde, 155 bitki taksonu tespit edilmiştir. Taksonların 15'i azalıcı, 9'u çoğalıcı ve 131 tanesinin de istilacı olduğu belirlenmiştir. Botanik kompozisyonda azalııların oranı \%14.86, çoğalıcıların oranı \%14.56 ve istilacıların oranı ise \%70.59 olarak belirlenmiştir. Saptanan taksonların \%11.0'ının buğdaygil, \%18.1'inin baklagil ve \%71.0'ının diğer familyalardan türlere ait olduğu ve sırasıyla en çok baklagiller (Fabaceae 28 adet), ballıbabagiller (Lamiaceae 20 adet), papatyagiller (Asteraceae 19 adet) ve buğdaygiller (Poaceae 17 adet) familyalarında yer alan bitkilerden olduğu saptanmıştır.

Yöneyler bakımından; tür çeşitliliğinin en fazla olduğu yöneyin 90 tür ile kuzey yöneyi olduğu, bunu 83 tür ile batı, 74 tür ile doğu ve 71 tür ile güney yöneylerinin takip ettiği belirlenmiştir. Yükseltiler bakımından; üçüncü yükseltilerin (1704 m) 102 tür ile en zengin çeşitliliğine sahip olduğu, bunu 85 tür ile ikinci yükseltilerin $(1876 \mathrm{~m})$ takip ettiği, en düşük değeri ise 80 tür ile birinci yükseltilerin $(1992 \mathrm{~m})$ verdiği gözlenmiştir. Çalışmada; batı ve kuzey yöneylerinin tür varlığı açısından daha zengin olduğu, yükseltiler bakımından ise aşağılara doğru inildikçe tür zenginliğinin arttığı tespit edilmiştir.
\end{abstract}

Anahtar Kelimeler: Bingöl, Mera, Takson, Yöney, Yükselti

\section{Determination of Plant Species at Different Direction and Altitudes of Pastures of Yelesen and Dikme Villages in Bingöl}

\begin{abstract}
This study was conducted to compare different directions and altitudes of a pasture land for identification plant species in Yelesen and Dikme villages, Bingöl in 2012 and 2013. Total 155 plant taxa of 96 genus from 29 plant families were identified in the two year study. 15 taxa were decreasers, 9 taxa were increasers and 131 taxa were invaders. Decreasers, increasers, and invaders had 14.86\%, 14.54\% and $70.59 \%$, respectively in the botanical composition. Identified $\% 11.0$ taxa were grasses, $\% 18.1$ taxa were legumes and \%71.0 taxa were other family crops. The majority of the species Fabaceae (28), Lamiaceae (20), Asteraceae (19) and Poaceae (17) were identified as belonging to the family.

In terms of the directions; the diversity of species is highest in the north direction with 90 species, west with 83 species, east with 74 species and south with 71 species were followed. In terms of the altitudes; third altitudes $(1704 \mathrm{~m}$ ) with 102 species have the richest diversity, it was followed by a second altitudes $(1876 \mathrm{~m})$ with 85 species, the lowest value were given by first altitudes (1992 m) with 80 species. In the study; west and north directions to be richer than the other directions in terms of the presence of species, species richness in terms of altitudes were found increased that towards the heights down.
\end{abstract}

Key Words: Bingöl, Altitude, Direction, Pasture, Taxa 


\section{Giriş}

Doğu Anadolu Bölgesi iklim ve topoğrafik özelliklerinden dolayı tarımın hayvancılık koluna daha elverişli bir bölgedir. Bu bölgede, diğer bölgelerimizde olduğu gibi, hayvancılığın ekonomik olarak yapılabilmesi büyük oranda kaba yem ihtiyacının karşılanmasına bağlıdır. Kaba yem ihtiyacının karşılanabileceği en önemli doğal kaynak alanları olarak karşımıza mera alanları çıkmaktadır. Mera alanlarında sürdürülebilirliğin sağlanması, çeşitli nedenlerden dolayı verimi azalan meraların ıslah edilebilmesi ve bunların verim ve kalitelerinin belirlenebilmesi için mera alanlarındaki bitki türlerinin tanınması gerekmektedir. Bu amaçlar doğrultusunda meralarda daha önce yapılan çalışmalarda, meraların baktıkları yöneylerin ve farklı yükseltilerinin gerek bitki varlığı açısından gerekse de baklagil, buğdaygil ve diğer familya bitkilerine ait oranları açısından farklılıklar gösterdiği görülmektedir.

Örneğin; Erkun (1971) tarafından Hakkari ve Van illerindeki 1900, 2200 ve 2500 m yüksekliklerdeki meraların bitki örtüsünü saptamak amacıyla yürütülen çalışmada, yüksekliğin artmasına bağlı olarak bitki ile kaplı alan oranının da değiştiği, Fayetörbay (2007) tarafından Erzurum Palandöken dağında farklı rakımlara $(3000 \mathrm{~m}, 2500 \mathrm{~m}$, 2000 m) sahip üç farklı mera alanında yürütülen çalışmada, rakım düştükçe bitkilerin toprağı kaplama alanlarının arttığı, Babalık (2008) tarafından Isparta ilinde farklı yükseklikteki (1050-1200 m, 1400-1500 m ve 1600-1750 m) meralarda 42 familyaya ait 242 bitki taksonunun tespit edildiği ve Aydın (2014) tarafından Diyarbakır Karacadağ'da sekiz farklı yükseltide yürütülen çalışmada en fazla takson sayısının $1510 \mathrm{~m}$ ve $1887 \mathrm{~m}$ yükseklikteki rakımlardan elde edildiği bildirilmiştir.
Yöneyler ile ilgili olarak; Gökkuş ve ark. (1993) tarafından Erzurum koşullarında yükseklik, eğim ve yöneyin mera vejetasyonlarına etkileri üzerine yapılan bir çalışmada; buğdaygillerin en fazla güney ve doğu, baklagillerin güney, diğer familya bitkilerinin ise kuzey ve batı yöneyinde bulunduğu, Çınar (2001) tarafından Adana ilinde doğal bir meranın dört farklı yöneyinin karşılaştırılması amacıyla yürütülen araştırmada 19 familyaya ait 53 cins ve 77 farklı bitki türünün saptandığı, Uslu (2005) tarafından Kahramanmaraş ilinde, incelenen merada 21 familyaya ait 54 cinsin 68 farklı türünün saptandığı, buğdaygillerin en fazla batı, baklagillerin en fazla kuzey, diğer familya bitkilerinin ise en fazla güney yöneyinde bulunduğu, Türker (2006) tarafından Mersin ilinde buğdaygillerin en fazla kuzey yöneyinde, baklagillerin en fazla kuzeydoğu ve diğer familya bitkilerinin ise en fazla güneybatı yöneyinde bulunduğu, incelenen alanda 25 familyaya ait 63 cins ve 83 bitki türünün tespit edildiği ve Ağın (2012) tarafından Bingöl ilinde bir meranın üç farklı yöneyinin karşılaştırıldığı araştırmada, baklagillerin en fazla güney, buğdaygillerin en fazla doğu yöneyinde olduğu ve merada 11 familyaya ait 26 cins ve 28 farklı bitki türünün saptandığı bildirilmiştir.

Sonuç itibari ile bu çalışmada Bingöl koşullarında hem yöneylerin ve hem de yükseltilerin, gerek bitki varlığı üzerinde ve gerekse de familyaların dağılımı üzerinde nasıl bir etki gösterdiği belirlenmeye çalışılmıştır.

\section{Materyal ve Metot}

Bu araştırma; Bingöl il merkezine bağlı Yelesen ve Dikme köylerinin ortak meralarında yürütülmüştür. Yelesen ve Dikme köyleri Bingöl merkezinin batısında yer almakta olup, Dikme köyü merkeze 35 
$\mathrm{km}$ uzaklıkta ve ortalama $1650 \mathrm{~m}$, Yelesen köyü ise merkeze $30 \mathrm{~km}$ uzaklıkta olup, ortalama 1810 m yüksekliğindedir. Araştırma ile ilgili arazi çalışmaları 2012 ve 2013 yıllarında Haziran ayının ilk haftasında, bitkilerin çiçeklenme döneminde yürütülmüştür. Çalışma alanı engebeli bir topografyaya sahip olup, eğimler kısa mesafelerde \%10-30 arasında değişim göstermiştir.

Bingöl iline ait bazı iklim verileri Meteoroloji Müdürlüğünden temin edilmiştir. Araştırma alanının iklim verilerine bakıldığında; Bingöl ilinin uzun yıllar (19602012) aylık ortalama sıcaklığının $12.01{ }^{\circ} \mathrm{C}$, toplam yağış miktarının $942.30 \mathrm{~mm}$ ve ortalama nispi nem değerinin ise \%57.15 olduğu görülmektedir. Araştırmanın yürütüldüğü 2012 ve 2013 yıllarında, uzun yıllar ortalamasına yakın sıcaklık (2012 yilında $12.70{ }^{\circ} \mathrm{C}, 2013$ yilında $13.29{ }^{\circ} \mathrm{C}$ ) ve nispi nem değerleri (2012 yılında \%53.59, 2013 yılında \%50.05) elde edilmiştir. Ancak Bingöl ili, çalışmanın yürütüldüğü 2012 yılında uzun yıllar ortalamasının biraz üstünde yağış almış olmasına rağmen (1074 mm), 2013 yılında uzun yıllar ortalamasının altında bir yağış miktarı aldığı $(652 \mathrm{~mm}$ ) görülmüştür.

Araştırma konusu mera alanlarında, 4 yöney ve 3 yükselti olmak üzere her yıl için toplam 12 adet toprak örnekleri $0-30 \mathrm{~cm}$ derinlikten alınmıştır. Elde edilen örneklerin analizi, Bingöl Üniversitesi Ziraat Fakültesi Toprak-Bitki Analiz Laboratuvarında yapılmıştır. Analiz sonuçları, Karaman ve Brohi (2004) ile Karaman (2012) tarafından belirlenen sınır değerler esas alınarak değerlendirilmiştir. Analiz sonuçlarına göre; tüm yöneylerin ve yükseltilerin toprak yapısının killi-tınlı yapıda olduğu, EC (tuzluluk) oranı "tuzsuz" (\%0.060), pH içeriklerinin nötre yakın (6.89), kireç $\left(\mathrm{CaCO}_{3}\right)$ seviyesinin "orta" (\%7.27), organik madde (OM) içeriklerinin "orta" (\%2.57), azot (N) açısından "yeterli" (1.30 g/kg), fosfor açısından "az" seviyede $(5.00 \mathrm{~kg} / \mathrm{da})$ ve potasyum açısından "yeterli" $(46.07 \mathrm{~kg} / \mathrm{da})$ olduğu tespit edilmiştir.

Çalışma alanında öncelikle yamaçların baktıkları yön esas alınarak kuzey, güney, doğu ve batı olmak üzere dört farklı yöney belirlenmiş, belirlenen her yöneye ait farklı yüksekliklerde (ortalama olarak; 1.Yükseltiler $=1992 \mathrm{~m}$, 2.Yükseltiler=1876 m, 3.Yükseltiler=1704 m) üç mera kesiminin tespiti yapılmıştır. Böylece Yelesen ve Dikme köylerinin ortak meralarını temsil edecek nitelikte on iki mera kesimi belirlenmiştir. Araştırma alanının vejetasyon ölçümü "nokta (nokta çerçeve) yöntemine" göre yapılmıştır. Bu yöntem farklı yer ve zamanlarda Kendir (1995), Başbağ ve ark. (1997), Dirihan (2000), Ateş (2001), Başbağ ve Çelik (2001), Türk ve ark. (2003), Gür (2007), Altın ve ark. (2010) ve Aydın (2014) tarafından kullanılmıştır. Belirlenen her mera kesiminde şerit metre ile dört adet $50 \mathrm{~m}$ uzunluğunda hat çekilmiştir. Her hatta 100 gözlem olmak üzere bir mera kesimi için 400, tüm çalışma alanı için ise toplam 4800 noktada gözlem yapılmıştır.

Çalışma esnasında karşılaşılan bitkilerin önemli bir kısmı merada teşhis edilemediğinden, bu bitkilere birer kod verilmiş ve çalışma tamamlanmıştır. Teşhis edilemeyen bitkilerden alınan örneklerin teşhisi Dicle Üniversitesi Fen Fakültesi Biyoloji Bölümünde yapılmıştır.

\section{Araştırma Bulguları ve Tartışma}

iki yıllık çalışma neticesinde farklı yöneylerde ve yükseltilerde saptanan bitkilere ait familya, cins, tür, buğdaygil, baklagil ve diğer familya bitkileri sayıları Çizelge 1'de verilmiştir. Çizelge 1'de görüldüğü üzere, incelenen 4 yöney ve her 
yöneye ait 3 yükseltideki meralarda toplam 29 bitki familyasının 96 farklı cinsten 155 bitki taksonu tespit edilmiştir. Saptanan türlerin 17'sinin buğdaygil (\%11.0), 28'inin baklagil (\%18.1) ve 110'unun diğer familya bitkilerine (\%71.0) ait olduğu belirlenmiştir.

Çizelge 1. Çalışma alanında saptanan bitkilerin familya, cins, tür, buğdaygil, baklagil ve diğer familyalara ait sayıları

Table 1. Numbers of the family, genus, species, grasses, legumes and other family plants which identified in the study area

\begin{tabular}{lcccccc}
\hline & $\begin{array}{c}\text { Familya } \\
\text { Family }\end{array}$ & $\begin{array}{c}\text { Cins } \\
\text { Genus }\end{array}$ & $\begin{array}{c}\text { Tür } \\
\text { Species }\end{array}$ & $\begin{array}{c}\text { Buğdaygil } \\
\text { Grasses }\end{array}$ & $\begin{array}{c}\text { Baklagil } \\
\text { Legumes }\end{array}$ & $\begin{array}{c}\text { Diğer familya } \\
\text { Other family }\end{array}$ \\
\hline Kuzey / North & 21 & 66 & 90 & 10 & 15 & 65 \\
Güney / South & 21 & 53 & 71 & 8 & 11 & 52 \\
$\begin{array}{l}\text { Doğu / East } \\
\text { Batı / West }\end{array}$ & 20 & 55 & 74 & 10 & 11 & 53 \\
\hline Toplam / Total & 22 & 62 & 83 & 12 & 14 & 57 \\
\hline & 29 & 96 & 155 & $17(\% 11.0)$ & $28(\% 18.1)$ & $110(\% 71.0)$ \\
\hline $\begin{array}{l}\text { 1. Yükseltiler 1st } \\
\text { altitude }\end{array}$ & 19 & 57 & 80 & 15 & 8 & 57 \\
$\begin{array}{l}\text { 2. Yükseltiler } \\
\text { 2st altitude }\end{array}$ & 21 & 62 & 85 & 13 & 16 & 56 \\
$\begin{array}{l}\text { 3. Yükseltiler } \\
\text { 3st altitude }\end{array}$ & 24 & 67 & 102 & 11 & 21 & 70 \\
\hline \multicolumn{1}{l}{ Toplam / Total } & 29 & 96 & 155 & 17 (\%11.0) & $28(\% 18.1)$ & 110 (\%71.0) \\
\hline
\end{tabular}

Tür çeşitliliğinin en fazla olduğu yöneyin 90 tür ile kuzey yöneyi olduğu, bunu 83 tür ile batı yöneyi ve 74 tür ile doğu yöneyinin takip ettiği görülmektedir. En az tür çeşitliliğine de 71 adet ile güney yöneyi sahip olmuştur. Buğdaygil zenginliği açısından 12 tür ile batı yöneyi en yüksek değeri vermiş, bunu 10 tür ile kuzey ve doğu yöneyleri takip etmiştir. En düşük değeri ise 8 adet ile güney yöneyi vermiştir. Baklagil açısından da en zengin yöney 15 tür ile kuzey yöneyi bulunmuş olup, bunu 14 tür ile batı yöneyi takip etmiştir. En düşük değeri de 11 adet ile güney ve doğu yöneyleri vermiştir.

Yükseltiler arasında bir karşılaştırma yapıldığında; üçüncü yükseltilerin 102 tür ile en zengin çeşitliliğine sahip olduğu, bunu da 85 tür ile ikinci yükseltilerin takip ettiği görülmektedir. Tür zenginliği açısından en düşük değeri de 80 tür ile birinci yükseltiler vermiştir. Buğdaygil zenginliği açısından en yüksek değerleri 15 tür ile birinci yükseltiler vermiş olup, bunu 13 tür ile ikinci yükseltiler takip etmiştir. En düşük değeri ise 11 tür sayısı ile üçüncü yükseltiler vermiştir. Baklagil zenginliği açısından en yüksek değerleri 21 tür ile üçüncü yükseltiler vermiş olup, bunu 16 tür ile ikinci yükseltiler takip etmiştir. En düşük değeri ise 8 tür sayısı ile birinci yükseltiler vermiştir.

Kuzey ve batı yöneylerinin gerek tür zenginliği gerekse de baklagil ve buğdaygil familyasına ait bitkilerin varlığı açısından daha zengin olduğu tespit edilmiştir. Bu yöneylerin farklı toprak ve topoğrafik yapıya sahip olması, yerleşim yerlerinden uzak olması ve otlatma baskısının bu yöneylerde daha az olması bu duruma neden olarak gösterilebilir. Yükseltiler açısından baktığımızda da tür zenginliğinin yükseklerden aşağılara doğru arttığı görülmektedir. 
Farklı yöneylerde ve yükseltilerde saptanan bitkilerin grupları ve ömür

durumlarına ait bilgiler Çizelge 2'de verilmiştir.

Çizelge 2. Çalışma alanında saptanan azalıcı, çoğalıcı, istilacı bitkiler ile çok yıllık ve tek yıllık bitki sayıları

Table 2. Numbers of the decreaser, increaser, invasive, perennial and annual plants which identified in the study area

\begin{tabular}{lcccccc}
\hline & $\begin{array}{c}\text { Azalııı } \\
\text { Decreasers }\end{array}$ & $\begin{array}{c}\text { Çoğalıcı } \\
\text { Increasers }\end{array}$ & $\begin{array}{c}\text { İstilacı } \\
\text { Invaders }\end{array}$ & $\begin{array}{c}\text { Toplam } \\
\text { Total }\end{array}$ & $\begin{array}{c}\text { Çok Yıllık } \\
\text { Perennial }\end{array}$ & $\begin{array}{c}\text { Tek Yıllık } \\
\text { Annual }\end{array}$ \\
\hline Kuzey/North & 10 & 6 & 74 & 90 & 61 & 29 \\
Güney/South & 7 & 6 & 58 & 71 & 51 & 20 \\
$\begin{array}{l}\text { Doğu / East } \\
\text { Batı/West }\end{array}$ & 6 & 6 & 62 & 74 & 52 & 21 \\
\hline Toplam/Total & 10 & 6 & 67 & 83 & 59 & 24 \\
\hline & 15 & 9 & 131 & 155 & $107(\% 69.0)$ & $47(\% 30.3)$ \\
\hline $\begin{array}{l}\text { 1. Yükseltiler } \\
\text { 1st altitude }\end{array}$ & 6 & 6 & 68 & 80 & 56 & 23 \\
$\begin{array}{l}\text { 2. Yükseltiler } \\
\text { 2st altitude }\end{array}$ & 13 & 5 & 67 & 85 & 58 & 27 \\
$\begin{array}{l}\text { 3. Yükseltiler } \\
\text { 3st altitude }\end{array}$ & 14 & 6 & 82 & 102 & 66 & 36 \\
\hline Toplam / Total & 15 & 9 & 131 & 155 & $107(\% 69.0)$ & 47 (\%30.3) \\
\hline
\end{tabular}

Çizelge 2'den anlaşılacağı üzere; çalışma alanını teşkil eden farklı 4 yöney ve her yöneye ait 3 yükseltide saptanan 155 türün $15^{\prime}$ inin azalıcl, 9'unun çoğalıcı ve 131 'inin istilacı olduğu belirlenmiştir. Botanik kompozisyonda azalıcıların oranı \%14.86, çoğalıcıların oranı $\% 14.54$ ve istilacıların oranı ise \%70.59 olarak belirlenmiştir. Tespit edilen türlerin 47'si tek yıllık (\%30.3), 107'siçok yıllık (\%69.0) ve 1 tanesi de parazittir (\%0.6).

Azalıc bitkilerin en yüksek değerlerini, kuzey ile batı yöneylerinde ve ikinci ile üçüncü yükseltilerde verdikleri, çoğalıcı bitkilerin meranın yöneylerinde ve yükseltilerinde fazla bir farklılık göstermediği, istilacı bitkilerin ise en yüksek değerlerini kuzey ve batı yöneylerinde, birinci ve üçüncü yükseltilerde verdikleri tespit edilmiştir. Genel olarak çok yıllık ve tek yıllık bitkilerin en yüksek değerlerini kuzey ve batı yöneyleri ile ikinci ve üçüncü yükseltilerde verdikleri görülmektedir. Kuzey ve batı yöneyleri ile ikinci ve üçüncü yükseltilerde yüksek değerler elde edilmesi, bu yöney ve yükseltilerdeki tür zenginliğinden kaynaklanmaktadır.

Çalışma alanında azalıcı bitkilerden çok çoğalıcı ve istilacı türlere rastlanmaktadır. Azalıcılar hayvanların severek otladığı bol üretim gücüne sahip türlerdir (Değer Sayısı 710). Çoğalıcılar hayvanların otlamada isteksiz davrandığı türlerden oluşmaktadır (Değer Sayısı 4-6). İstilacılar ise hayvanların otlamadığı lezzetsiz, dikenli veya zehirli türlerden meydana gelmektedir (Değer Sayısı 0-3). Ayrıca tek yılık bitkiler istilacı türler olarak kabul edilmektedir (Holechekve ark., 1995). Mera hayvanları öncelikle alandaki lezzetli (azalıcı bitkiler) türleri, daha sonra az lezzetli (çoğalıcı bitkiler) türleri tercih etmektedirler. Bunun sonucunda alandaki lezzetli ve tercih edilen bitkiler aşırı derecede azalmakta buna karşılık çoğalıcı ve istilacı 
türler alanı kaplamaktadır (Şengönül ve ark., 2009).

Daha önce yapılan benzer çalışmalarda; Babalık (2008) tarafından Isparta ilinde yürütülen mera çalışmasında tespit edilen 242 adet taksonun $18^{\prime}$ inin azalıcı, 45'inin çoğalıcı ve 179 'unun istilacı, Şengönül ve ark. (2009) tarafından Bartın meralarında yürütülen çalışmada azalıcıları \%23.96, çoğalıcıları \%32.02 ve istilacıları \%44.02, Ünal ve ark. (2012a) tarafından Ankara ilinde yürütülen mera çalışmalarında azalıcı ve çoğalıcı türlerin oranlarını sırasıyla \%10.24 ve \%25.71, Ünal ve ark. (2012b) tarafından Çankırı meralarında yürütülen çalışmada azalıcı ve çoğalıcı türlerin oranlarını da sırasıyla \%14.72 ve \%24.80 olarak tespit etmişlerdir.

Farklı yöneylerde ve yükseltilerde saptanan bitki türlerinin tür adları, familyaları, ömürleri, tespit edildikleri yöney ve yükseltiler ile toprağı kaplama oranları ve botanik kompozisyondaki oranları Çizelge 3'te verilmiştir. Bitki ile kaplı alan oranı \%68.19 olarak tespit edilmiştir. Tespit edilen türlerin çoğunluğunun Fabaceae (28 adet), Lamiaceae (20 adet), Asteraceae (19 adet) ve Poaceae (17 adet) familyalarına ait oldukları saptanmıştır.

Çalışılan tüm yöney ve yükseltilere ait mera kesimlerinde en çok karşılaşılan baklagiller; Astragalus gummifer (\%11.21), Trifolium campestre (\%2.27), Astragalus lineatus var. lineatus (\%1.13) olurken, en çok karşılaşılan buğdaygiller; Hordeum bulbosum (\%4.42), Poa bulbosa (\%4.39), Bromus squarrosus (\%1.39) ve Bromus tomentellus (\%1.39) olmuştur. En çok karşılaşılan diğer familya bitkilerinin ise Plantago lanceolata (\%8.14), Sanguisorba minor subsp. lasiocarpa (\%3.96) ve Eremurus spectabilis (\%3.92) olduğu tespit edilmiştir.

Çizelge 3. Farklı Yöneylerde ve Yükseltilerde Saptanan Bitki Türlerinin Tür Adları, Familyaları, Ömürleri, Tespit Edildikleri Yöneyler ve Yükseltiler ile Toprağı Kaplama ve Botanik Kompozisyondaki Oranları

Table 3. Species names, families, life time, plant species which identified different directions and altitudes, coverage of the earth and botanical composition rates

\begin{tabular}{|c|c|c|c|c|c|c|c|}
\hline & Azalıcılar* / Decreasers & $\begin{array}{c}\text { Familyası* } \\
\text { Family }\end{array}$ & $\begin{array}{c}\text { Ömrü* } \\
\text { Life }\end{array}$ & $\begin{array}{c}\text { Yöney } \\
\text { Direction }\end{array}$ & $\begin{array}{l}\text { Yükselti } \\
\text { Altitude }\end{array}$ & $\begin{array}{l}\text { TKO } \\
(\%)\end{array}$ & BKO (\%) \\
\hline 1 & Alopecurus arundinaceus & Poaceae & ÇY & $B$ & 1. 2 & 0.05 & 0,07 \\
\hline 2 & Bromus tomentellus & Poaceae & ÇY & G. D & 1. 2.3 & 0.89 & 1,39 \\
\hline 3 & Dactylis glomerata & Poaceae & ÇY & K.G.D.B & 1. 2.3 & 0.83 & 1,08 \\
\hline 4 & Hordeum bulbosum & Poaceae & ÇY & K. D. B & 1. 2.3 & 2.71 & 4,42 \\
\hline 5 & Lotus corniculatus & Fabaceae & ÇY & K. B & 2. 3 & 0.15 & 0,17 \\
\hline 6 & Lotus gebelia & Fabaceae & ÇY & G. D. B & 2. 3 & 0.65 & 0,83 \\
\hline 7 & Medicago sativa & Fabaceae & ÇY & G & 3 & 0.05 & 0,07 \\
\hline 8 & Medicago x varia & Fabaceae & ÇY & $\mathrm{B}$ & 3 & 0.14 & 0,17 \\
\hline 9 & Onobrychis fallax & Fabaceae & ÇY & K. G. D & 2. 3 & 0.19 & 0,25 \\
\hline 10 & Poa nemoralis & Poaceae & ÇY & K. B & 1. 2 & 0.24 & 0,29 \\
\hline 11 & Sanguisorba minor subsp. & Rosaceae & ÇY & K.G.D.B & 2. 3 & 2.80 & 3,96 \\
\hline 12 & Sanguisorba minor subsp. & Rosaceae & ÇY & K. G & 2. 3 & 0.41 & 0,68 \\
\hline 13 & Trifolium hybridum & Fabaceae & ÇY & $\mathrm{K}$ & 3 & 0.29 & 0,37 \\
\hline 14 & Trifolium pratense & Fabaceae & ÇY & K. B & 2. 3 & 0.54 & 0,83 \\
\hline 15 & Vicia cracca & Fabaceae & ÇY & K. B & 1. 2.3 & 0.20 & 0,30 \\
\hline \multicolumn{6}{|c|}{ Toplam/Total } & 10.13 & 14.86 \\
\hline \multicolumn{8}{|c|}{ Çoğalıcılar / Increasers } \\
\hline 1 & Cerastium glomeratum & Caryophyllaceae & TY & K. G. D & 1.2 & 0.43 & 0,58 \\
\hline 2 & Cerastium perfoliatum & Caryophyllaceae & TY & K. D. B & 1. 3 & 0.22 & 0,27 \\
\hline 3 & Coronilla orientalis & Fabaceae & ÇY & G. D. B & 1. 2.3 & 0.17 & 0,22 \\
\hline
\end{tabular}




\begin{tabular}{|c|c|c|c|c|c|c|c|}
\hline \multicolumn{3}{|c|}{ Çoğalıcılar / Increasers } & \multirow[b]{2}{*}{ ÇY } & \multirow[b]{2}{*}{ K. G. B } & \multirow[b]{2}{*}{3} & \multirow[b]{2}{*}{0.45} & \multirow[b]{2}{*}{0,77} \\
\hline 4 & Coronilla sp. & Fabaceae & & & & & \\
\hline 5 & Medicago Iupulina & Fabaceae & ÇY & $\mathrm{K}$ & 3 & 0.01 & 0,01 \\
\hline 6 & Plantago lanceolata & Plantaginaceae & ÇY & K.G.D.B & 2.3 & 5.21 & 8,14 \\
\hline 7 & Poa bulbosa & Poaceae & ÇY & K.G.D.B & 1. 2.3 & 3.54 & 4,39 \\
\hline 8 & Poa trivialis & Poaceae & ÇY & G. D & 1. 2 & 0.10 & 0,14 \\
\hline 9 & Stipa holosericea & Poaceae & ÇY & $\mathrm{B}$ & 1 & 0.02 & 0,03 \\
\hline \multicolumn{6}{|c|}{ Toplam / Total } & 10.15 & 14.54 \\
\hline \multicolumn{3}{|c|}{ İstilacılar / Invaders } & & & & & \\
\hline 1 & Acantholimon acerosum & Plumbaginaceae & ÇY & K. G. B & 1.2 & 1.87 & 2,78 \\
\hline 2 & Acanthus dioscoridis & Acanthaceae & ÇY & D. B & 1. 3 & 0.07 & 0,14 \\
\hline 3 & Achillea millefolium & Asteraceae & ÇY & K. D. B & 1. 3 & 0.10 & 0,12 \\
\hline 4 & Achillea schischkinii & Asteraceae & ÇY & K.G.D.B & 2 & 0.12 & 0,19 \\
\hline 5 & Achillea vermicularis & Asteraceae & ÇY & K.G.D.B & 1. 2.3 & 1.95 & 2,95 \\
\hline 6 & Aegilops triuncialis & Poaceae & TY & $\mathrm{D}$ & 2.3 & 0.28 & 0,38 \\
\hline 7 & Alkanna orientalis & Boraginaceae & ÇY & G & 2 & 0.05 & 0,07 \\
\hline 8 & Alyssum contemptum & Brassicaceae & TY & G & 2 & 0.03 & 0,05 \\
\hline 9 & Alyssum hirsutum & Brassicaceae & TY & K. G & 1 & 0.13 & 0,21 \\
\hline 10 & Anchusa strigosa & Boraginaceae & ÇY & K. B & 3 & 0.06 & 0,08 \\
\hline 11 & Anthemis pseudocotula & Asteraceae & TY & K. B & 2. 3 & 0.17 & 0,20 \\
\hline 12 & Asperugo procumbens & Boraginaceae & TY & $\mathrm{K}$ & 3 & 0.02 & 0,02 \\
\hline 13 & Asperula arvensis & Rubiaceae & TY & K. G. D & 1. 3 & 0.06 & 0,11 \\
\hline 14 & Asperula xylorrhiza & Rubiaceae & ÇY & G. D & 3 & 0.19 & 0,37 \\
\hline 15 & Astragalus cephalotes & Fabaceae & ÇY & $\mathrm{D}$ & 3 & 0.02 & 0,03 \\
\hline 16 & Astragalus compactus & Fabaceae & ÇY & $\mathrm{D}$ & 2 & 0.13 & 0,17 \\
\hline 17 & Astragalus gummifer & Fabaceae & ÇY & K.G.D.B & 1. 2.3 & 7.18 & 11,21 \\
\hline 18 & Astragalus kurdicus & Fabaceae & ÇY & K. G. D & 1.2 & 0.58 & 0,74 \\
\hline 19 & Astragalus lineatus var. & Fabaceae & ÇY & K. G. D & 1. 2 & 0.62 & 1,13 \\
\hline 20 & Astragalus lineatus var. & Fabaceae & ÇY & $\mathrm{B}$ & 1. 2 & 0.15 & 0,21 \\
\hline 21 & Astragalus szovitsii & Fabaceae & ÇY & $\mathrm{D}$ & 1 & 0.05 & 0,07 \\
\hline 22 & Avena sativa & & & & & & \\
\hline 23 & Brassica elongata & Brassicaceae & ÇY & K. G. D & 1 & 0.14 & 0,18 \\
\hline 24 & Bromus danthoniae & Poaceae & TY & G. B & 1. 2.3 & 0.45 & 0,72 \\
\hline 25 & Bromus japonicus & Poaceae & TY & K. B & 1. 3 & 0.51 & 0,89 \\
\hline 26 & Bromus squarrosus & Poaceae & TY & K.G.D.B & 1. 2.3 & 1.12 & 1,39 \\
\hline 27 & Bromus tectorum & Poaceae & TY & $\mathrm{D}$ & 1 & 0.19 & 0,39 \\
\hline 28 & Bunium paucifolium var. & Apiaceae & ÇY & $\mathrm{K}$ & 2.3 & 0.04 & 0,05 \\
\hline 29 & Bunium paucifolium var. & Apiaceae & ÇY & K.G.D.B & 1. 2.3 & 0.64 & 0,83 \\
\hline 30 & Bunium verruculosum & Apiaceae & ÇY & G. D & 2.3 & 0.21 & 0,43 \\
\hline 31 & Carex nigra & Cyperaceae & ÇY & G & 3 & 0.09 & 0,12 \\
\hline 32 & Carex stenophylla & Cyperaceae & ÇY & $\mathrm{K}$ & 3 & 0.31 & 0,54 \\
\hline 33 & Centaurea behen & Asteraceae & ÇY & $\mathrm{D}$ & 3 & 0.26 & 0,35 \\
\hline 34 & Centaurea iberica & Asteraceae & ÇY & G & 3 & 0.05 & 0,07 \\
\hline 35 & Centaurea saligna & Asteraceae & ÇY & $\mathrm{K}$ & 3 & 0.12 & 0,13 \\
\hline 36 & Chardinia orientalis & Asteraceae & TY & K. G & 1. 2.3 & 0.34 & 0,48 \\
\hline 37 & Chenopodium murale & Chenopodiaceae & TY & $\mathrm{D}$ & 2 & 0.04 & 0,06 \\
\hline 38 & Cicer anatolicum & Fabaceae & ÇY & $\mathrm{K}$ & 2 & 0.03 & 0,05 \\
\hline 39 & Convolvulus arvensis & Convolvulaceae & ÇY & K.G.D.B & 2. 3 & 0.32 & 0,41 \\
\hline 40 & Coronilla sp. & Fabaceae & ÇY & K. G. B & 1. 2.3 & 0.54 & 0,90 \\
\hline 41 & Crataegus szovitsii & Rosaceae & ÇY & $\mathrm{D}$ & 2 & 0.05 & 0,07 \\
\hline 42 & Crepis armena & Asteraceae & ÇY & G & 3 & 0.84 & 1,36 \\
\hline 43 & Crepis foetida & Asteraceae & TY & B & 3 & 0.15 & 0,25 \\
\hline 44 & Crepis sancta & Asteraceae & TY & K. G. D & 1. 2.3 & 1.09 & 1,39 \\
\hline 45 & Crepis sp. & Asteraceae & TY & K. G. B & 1. 2.3 & 0.64 & 0,76 \\
\hline 46 & Cruciata taurica & Rubiaceae & ÇY & $\mathrm{D}$ & 1 & 0.06 & 0,08 \\
\hline 47 & Cyperus rotundus & Cyperaceae & ÇY & $\mathrm{K}$ & 2 & 0.04 & 0,05 \\
\hline 48 & Dactylorhiza iberica & Orchidaceae & ÇY & $\mathrm{K}$ & 3 & 0.01 & 0,01 \\
\hline 49 & Echinops pungens & Asteraceae & ÇY & G. D. B & 1. 2.3 & 0.95 & 1,73 \\
\hline 50 & Eremurus spectabilis & Liliaceae & ÇY & K.G.D.B & 1. 2.3 & 2.64 & 3,92 \\
\hline
\end{tabular}




\begin{tabular}{|c|c|c|c|c|c|c|c|}
\hline & İstilacılar* / Invaders & Familyası* & Ömrü* & Yöney & Yükselti & TKO & BKO (\%) \\
\hline 51 & Eryngium campestre & Apiaceae & ÇY & K.G.D.B & 1. 2.3 & 2.62 & 3,83 \\
\hline 52 & Euphorbia cheiradenia & Euphorbiaceae & ÇY & D. $\mathrm{K}$ & 1 & 0.21 & 0,37 \\
\hline 53 & Euphorbia denticulata & Euphorbiaceae & ÇY & K.G.D.B & 1. 2 & 0.33 & 0,41 \\
\hline 54 & Euphorbia virgata & Euphorbiaceae & ÇY & Güney & 3 & 0.03 & 0,04 \\
\hline 55 & Ferula communis & Apiaceae & ÇY & K. D. B & 1. 2 & 0.58 & 0,95 \\
\hline 56 & Fibigia macrocarpa & Brassicaceae & ÇY & B & 1 & 0.01 & 0,01 \\
\hline 57 & Filago sp. & Asteraceae & TY & K. B & 1. 3 & 0.13 & 0,16 \\
\hline 58 & Gagea villosa & Liliaceae & ÇY & K & 3 & 0.35 & 0,41 \\
\hline 59 & Galium aparine & Rubiaceae & TY & D. B & 1. 3 & 0.22 & 0,36 \\
\hline 60 & Galium consanguineum & Rubiaceae & ÇY & $\mathrm{K}$ & 3 & 0.05 & 0,09 \\
\hline 61 & Gundelia tournefortii var. & Asteraceae & ÇY & $\mathrm{K}$ & 3 & 0.06 & 0,07 \\
\hline 62 & Gundelia tournefortii var. & Asteraceae & ÇY & K.G.D.B & 1. 2.3 & 0.78 & 0,99 \\
\hline 63 & Haplophyllum armenum & Rutaceae & ÇY & B & 2 & 0.03 & 0,04 \\
\hline 64 & Helianthemum ledifolium & Cistaceae & TY & B & 3 & 0.03 & 0,04 \\
\hline 65 & Holesteum umbellatum & Caryophyllaceae & TY & K.G.D.B & 1. 2.3 & 0.40 & 0,49 \\
\hline 66 & Hordeum murinum & Poaceae & TY & K. D. B & 1. 2.3 & 0.68 & 0,79 \\
\hline 67 & Hypericum scabrum & Guttiferae & ÇY & K.G.D.B & 1. 3 & 0.16 & 0,20 \\
\hline 68 & Hypericum triquetrifolium & Guttiferae & ÇY & $\mathrm{K}$ & 1 & 0.04 & 0,07 \\
\hline 69 & Lallemantia iberica & Lamiaceae & TY & K. B & 1. 3 & 0.04 & 0,05 \\
\hline 70 & Lamium album & Lamiaceae & ÇY & G. B & 1 & 0.05 & 0,08 \\
\hline 71 & Lamium macrodon & Lamiaceae & TY & K & 1 & 1.10 & 1,48 \\
\hline 72 & Linum mucronatum & Linaceae & ÇY & $\mathrm{D}$ & 1 & 0.01 & 0,01 \\
\hline 73 & Medicago sp. & Fabaceae & TY & B & 3 & 0.01 & 0,01 \\
\hline 74 & Melilotus alba & Fabaceae & TY & G & 3 & 0.03 & 0,04 \\
\hline 75 & Mentha longifolia & Lamiaceae & ÇY & $\mathrm{K}$ & 3 & 0.06 & 0,07 \\
\hline 76 & Minuartia hamata & Lamiaceae & TY & K. D. B & 2. 3 & 0.29 & 0,37 \\
\hline 77 & Myosotis sp. & Boraginaceae & TY & K & 2 & 0.02 & 0,02 \\
\hline 78 & Nepeta sp. & Lamiaceae & ÇY & K.G.D.B & 1. 2.3 & 0.21 & 0,26 \\
\hline 79 & Nonea pulla & Boraginaceae & ÇY & B & 1. 3 & 0.05 & 0,07 \\
\hline 80 & Ononis spinosa & Fabaceae & ÇY & $\mathrm{D}$ & 2. 3 & 0.08 & 0,16 \\
\hline 81 & Onosma sericeum & Boraginaceae & ÇY & $\mathrm{K}$ & 3 & 0.01 & 0,01 \\
\hline 82 & Onosma trachytrichum & Boraginaceae & ÇY & G. B & 1. 3 & 0.16 & 0,27 \\
\hline 83 & Origanum acutidens & Lamiaceae & ÇY & $\mathrm{D}$ & 3 & 0.03 & 0,04 \\
\hline 84 & Origanum vulgare & Lamiaceae & ÇY & B & 2 & 0.03 & 0,04 \\
\hline 85 & Ornithogalum narbonense & Liliaceae & ÇY & K. G & 3 & 0.55 & 0,95 \\
\hline 86 & Orobanche anatolica & Orobanchaceae & - & $\mathrm{D}$ & 1 & 0.02 & 0,03 \\
\hline 87 & Papaver dubium & Papaveraceae & TY & $\mathrm{D}$ & 2 & 0.03 & 0,04 \\
\hline 88 & Papaver rhoeas & Papaveraceae & TY & G. D & 2. 3 & 0.07 & 0,09 \\
\hline 89 & Paracaryum sp. & Boraginaceae & ÇY & B & 2 & 0.02 & 0,03 \\
\hline 90 & Phlomis bruguieri & Lamiaceae & ÇY & K. B & 1 & 0.65 & 1,12 \\
\hline 91 & Phlomis linearis & Lamiaceae & ÇY & K.G.D.B & 1. 2.3 & 0.58 & 0,74 \\
\hline 92 & Phlomis pungens & Lamiaceae & ÇY & K.G.D.B & 1. 2.3 & 0.72 & 0,99 \\
\hline 93 & Phlomis rigida & Lamiaceae & ÇY & K.G.D.B & 1. 2.3 & 0.64 & 1,07 \\
\hline 94 & Polygonum arenastrum & Polygonaceae & TY & G. B & 1. 2 & 0.07 & 0,09 \\
\hline 95 & Polygonum cognatum & Polygonaceae & ÇY & B & 2 & 0.02 & 0,04 \\
\hline 96 & Potentilla recta & Rosaceae & ÇY & K. B & 2 & 0.29 & 0,43 \\
\hline 97 & Ranunculus arvensis & Ranunculaceae & TY & K. B & 2. 3 & 0.05 & 0,06 \\
\hline 98 & Ranunculus cuneatus & Ranunculaceae & ÇY & K. B & 1. 3 & 0.23 & 0,28 \\
\hline 99 & Ranunculus kotschyi & Ranunculaceae & ÇY & G & 3 & 0.13 & 0,16 \\
\hline 100 & Rhagadiolus angulosus & Asteraceae & TY & K. G. D & 1. 2.3 & 0.49 & 0,87 \\
\hline 101 & Rochelia disperma & Boraginaceae & TY & K. G & 2.3 & 0.08 & 0,10 \\
\hline 102 & Rumex acetosella & Polygonaceae & ÇY & K.G.D.B & 1. 2.3 & 0.55 & 0,73 \\
\hline 103 & Salvia macrochlamys & Lamiaceae & ÇY & B & 3 & 0.01 & 0,01 \\
\hline 104 & Salvia multicaulis & Lamiaceae & ÇY & B & 1 & 0.17 & 0,21 \\
\hline 105 & Salvia syriaca & Lamiaceae & ÇY & G. D & 3 & 0.55 & 0,98 \\
\hline 106 & Salvia trichoclada & Lamiaceae & ÇY & $\mathrm{K}$ & 2 & 0.04 & 0,07 \\
\hline 107 & Scorzonera mollis & Asteraceae & ÇY & K. D & 1.2 & 0.03 & 0,04 \\
\hline
\end{tabular}




\begin{tabular}{|c|c|c|c|c|c|c|c|}
\hline & İstilacılar* / Invaders & Familyası* & Ömrü* & Yöney & Yükselti & TKO & BKO (\%) \\
\hline 108 & Scutellaria orientalis & Lamiaceae & ÇY & Batı & 1 & 0.04 & 0,05 \\
\hline 109 & Sedum album & Crassulaceae & ÇY & $\mathrm{K}$ & 2.3 & 0.06 & 0,07 \\
\hline 110 & Silene spergulifolia & Caryophyllaceae & ÇY & K. G. B & 1. 2 & 0.14 & 0,18 \\
\hline 111 & Silene supina & Caryophyllaceae & ÇY & $\mathrm{B}$ & 1 & 0.04 & 0,05 \\
\hline 112 & Sisymbrium loeselii & Brassicaceae & ÇY & D. B & 1. 2 & 0.08 & 0,11 \\
\hline 113 & Stachys lavandulifolia & Lamiaceae & ÇY & G. D & 1 & 0.21 & 0,33 \\
\hline 114 & Taeniatherum caput- & Poaceae & TY & K. G. B & 1. 2.3 & 0.47 & 0,69 \\
\hline 115 & Thlaspi arvense & Brassicaceae & TY & K.G.D.B & 1. 2.3 & 0.77 & 0,98 \\
\hline 116 & Thymus kotschyanus & Lamiaceae & ÇY & K.G.D.B & 1. 2 & 1.05 & 1,65 \\
\hline 117 & Torilis leptophylla & Apiaceae & ÇY & $\mathrm{D}$ & 3 & 0.19 & 0,25 \\
\hline 118 & Trifolium arvense & Fabaceae & TY & K. B & 3 & 0.38 & 0,53 \\
\hline 119 & Trifolium campestre & Fabaceae & TY & K. G & 2.3 & 1.52 & 2,27 \\
\hline 120 & Trifolium hirtum & Fabaceae & TY & $\mathrm{K}$ & 3 & 0.09 & 0,14 \\
\hline 121 & Trifolium nigrescens & Fabaceae & TY & $\mathrm{D}$ & 2 & 0.03 & 0,04 \\
\hline 122 & Trigonella foenum- & Fabaceae & TY & B & 3 & 0.01 & 0,01 \\
\hline 123 & Turgenia latifolia & Apiaceae & TY & B & 2. 3 & 0.05 & 0,07 \\
\hline 124 & Tussilago farfara & Asteraceae & ÇY & G. D & 1. 2 & 0.04 & 0,05 \\
\hline 125 & Vaccaria hispanica var. & Caryophyllaceae & TY & $\mathrm{D}$ & 3 & 0.03 & 0,04 \\
\hline 126 & Vaccaria hispanica var. & Caryophyllaceae & TY & $\mathrm{D}$ & 3 & 0.16 & 0,32 \\
\hline 127 & Verbascum speciosum & Scrophulariaceae & ÇY & B & 1 & 0.04 & 0,05 \\
\hline 128 & Veronica orientalis & Scrophulariaceae & ÇY & K.G.D.B & 1. 3 & 0.24 & 0,31 \\
\hline 129 & Zingeria biebersteiniana & Poaceae & TY & $\mathrm{K}$ & 2.3 & 0.18 & 0,23 \\
\hline 130 & Ziziphora capitata & Lamiaceae & TY & K.G.D.B & 1. 2.3 & 0.76 & 0,98 \\
\hline 131 & Ziziphora clinopodioides & Lamiaceae & ÇY & K. G. D & 1. 2.3 & 0.43 & 0,55 \\
\hline \multicolumn{6}{|c|}{ Toplam / Total } & 47.92 & 70.59 \\
\hline \multicolumn{4}{|c|}{${ }^{*}$ :Serin ve ark. 2005 , Serin ve ark. 2008} & \multicolumn{2}{|c|}{ Genel } & 68.19 & 100.00 \\
\hline
\end{tabular}

\section{Sonuçlar}

Sonuç itibariyle kuzey ve batı yöneylerinin gerek tür gerekse de buğdaygil ve baklagil varlığı açısından diğer yöneylere göre daha zengin olduğu, düşük rakıma sahip olan üçüncü yükseltilerin de diğer yükseltilere göre daha zengin olduğu ve rakım arttıkça tür sayısının da azaldığı tespit edilmiştir. Çalışma alanında hayvan besleme açısından önem arz eden azalıcı ve çoğalıcı bitki grubunda olan tür varlığının az olduğu, istilacı nitelikteki türlerin oranının ise fazla olduğu belirlenmiştir. Azalıcı ve çoğalıcı grubuna giren bitkilerin en yüksek değerlerini tür varlığının daha iyi olduğu kuzey ve batı yöneyleri ile ikinci ve üçüncü yükseltilerde verdiği tespit edilmiştir.

Gerek baklagil ve buğdaygil grubundaki bitki türlerinin gerekse bu gruplar içerisindeki azalıcı ve çoğalıcı bitki türlerinin sayısının artırılması için meralardan taşların toplatılması ve bazı istilacı diken formundaki bitkilerin uzaklaştırılmasının yanı sıra bilimsel esaslara dayalı otlatma sistemlerinin bu alanlarda uygulanmasının olumlu etkisi olacağı öngörülmektedir. Ayrıca çalışma alanındaki toprakların verimlilik açısından önemli problemler içermediği ancak bununla birlikte, bu arazilerde mera ıslah ve amenajman çalışmaları planlanacaksa fosfor takviyesi yapılması tavsiye edilmektedir.

\section{Ekler}

Bu Çalışma, "Bingöl İli Merkez İlçesi Yelesen-Dikme Köyleri Meralarının Farklı Yöney ve Yükseltilerindeki Bitki Tür ve Kompozisyonları ile Ot Verim ve Kalitelerinin Belirlenmesi" adlı doktora çalışmasının bir bölümüdür. 
Bu çalışma Dicle Üniversitesi Bilimsel Araştırma Projeleri Koordinatörlüğü tarafından 12-ZF-14 nolu proje ile desteklenmiştir.

\section{Kaynaklar}

Ağın, Ö., 2012. Bingöl İli Yedisu İlçesi Karapolat Köyü Merasının Verim ve Botanik Kompozisyonunun Saptanması. Yüksek Lisans Tezi, Bingöl Üniversitesi Fen Bilimleri Enstitüsü, Tarla Bitkileri Anabilim Dalı, Bingöl.

Ateş, A., 2001. Ardahan Ili Sulakyurt Köyünde Korunan ve Otlatılan Meralardaki Bitki Örtüsü ve Verim Güçlerinin Saptanması. Yüksek Lisans Tezi, Dicle Üniversitesi Fen Bilimleri Enstitüsü Tarla Bitkileri Anabilim Dalı, Diyarbakır.

Altın,M.,Tuna,C., Gür, M., 2010. Tekirdağ Taban ve Kıraç Meralarının Verim ve Botanik Kompozisyonuna Gübrelemenin Etkisi. Tekirdağ Ziraat Fakültesi Dergisi, 7(2), 191198.

Aydın, A., 2014. Karacadağ'ın Farklı Yükseltilerindeki Meralarında Bitki Tür ve Kompozisyonları ile Ot Verim ve Kalitelerinin Belirlenmesi. Doktora Tezi, Dicle Üniversitesi Fen Bilimleri Enstitüsü, Tarla Bitkileri Anabilim Dalı, Diyarbakır.

Babalık, A.A., 2008. Isparta Yöresi Meralarının Vejetasyon Yapısı ile Toprak Özellikleri ve Topoğrafik Faktörler Arasındaki İlişkiler. Doktora Tezi, Süleyman Demirel Üniversitesi Fen Bilimleri Enstitüsü, Orman Mühendisliği Anabilim Dalı, Isparta.

Başbağ, M., Gül, i., Saruhan, V., 1997. Diyarbakır'da Korunan Bir Mer'a Alanında Bitki Tür ve Kompozisyonları ile $\mathrm{Ot}$ Verimlerinin İncelenmesi Üzerine Bir Araştırma. Türkiye 2. Tarla Bitkileri Kongresi, s. 499-503, Samsun.

Başbağ, M., Çelik, M.A., 2001. Diyarbakır ili Gözalan Köyünde Korunan ve Otlatılan Meralardaki Bitki Tür ve Kompozisyonları ile Ot Verimlerinin İncelenmesi Üzerine Bir Araştırma. Türkiye 4. Tarla Bitkileri Kongresi, Cilt III, s.187-192, Tekirdağ.

Çınar, S., 2001. Adana ili Tufanbeyli ilçesi Hanyeri Köyü Merasında Verim ve Botanik Kompozisyonun Saptanması Üzerine Bir Araştırma. Yüksek Lisans Tezi, Çukurova Üniversitesi Fen Bilimleri Enstitüsü, Tarla
Bitkileri Anabilim Dalı, Adana.

Dirihan, S., 2000. Diyarbakır Pirinçlik Garnizonunda Korunan ve Otlatılan Meralarda Bitki Tür ve Kompozisyonları ile Ot Verimlerinin İncelenmesi Üzerine Bir Araştırma. Yüksek Lisans Tezi, Dicle Üniversitesi Fen Bilimleri Enstitüsü Tarla Bitkileri Anabilim Dalı, Diyarbakır.

Erkun, V., 1971. Hakkari ve Van Illerinde Mera Araştırmaları. Tarım Bakanlığı Ziraat İ̧̧leri Gn. Müd. Yayınları, G.13, Ankara.

Holechek, J.L., Pieper, R.D., Herbel, C.H., 1995. Range Management Principles and Practices. Prentice Halllnc., $526 \mathrm{p}$.

Fayetörbay, D., 2007. Palandöken Dağlarında Farklı Rakıma Sahip Mera Kesimlerinin Bitki Örtülerinin Karşılaştırılması. Yüksek Lisans Tezi, Atatürk Üniversitesi Fen Bilimleri Enstitüsü, Tarla Bitkileri Anabilim Dalı, Erzurum.

Gökkuş, A., Avcı, M., Aydın, A., Mermer, A., Ulutaş, Z., 1993. Yükseklik Eğim ve Yöneyin Mera Vejetasyonlarına Etkileri. Tarım Orman Köyişleri Bakanlığı Doğu Anadolu Tarımsal Araştırma Enstitüsü, Yayın No:13, A.Ü. Ziraat Fakültesi Ofset Tesisi, Erzurum.

Gür, M., 2007. Yörükler Köyü Doğal Mera Vejetasyonunun Botanik Kompozisyonu ve Verim Potansiyeli Üzerine Bir Araştırma. Yüksek Lisans Tezi, Namık Kemal Üniversitesi Fen Bilimleri Enstitüsü, Tarla Bitkileri Anabilim Dalı, Tekirdağ.

Karaman, M.R., Brohi, A.R., 2004. 3.Ulusal Gübre Kongresi. Tarım-Sanayi-Çevre Bildiri Kitabı 2.Cilt, Sayfa:1416, Tokat.

Karaman, M.R., 2012. Bitki Besleme. Gübretaş Rehber Kitaplar Dizisi:2. Editör: Zengin, M., Toprak ve Bitki Analiz Sonuçlarının Yorumlanmasında Temel illkeler (Bölüm 12), Sayfa: 874.

Kendir, H., 1995. Bazı Mera Vejetasyon Ölçme Metotlarında Optimum Örnek Sayısının Saptanması. Doktora Tezi, Ankara Üniversitesi Fen Bilimleri Enstitüsü, Tarla Bitkileri Anabilim Dalı, Ankara.

Serin, Y., Zengin, H., Tan, M., Koç, A., Erkovan, H.i., 2005. Çayır ve Mera Bitkileri Klavuzu. Tarım ve Köyşşleri Bakanlığı Tarımsal Üretim ve Geliştirme Genel Müd. Yayınları, Ankara.

Serin, Y., Tan, M., Koç, A., Zengin, H., 2008. Türkiye'nin Çayır ve Mera Bitkileri. Tarım ve Köyişleri Bakanlığı Tarımsal Üretim ve Geliştirme Genel Müd. Yayınları, Ankara. 
Şengönül, K., Kara, Ö., Palta, Ş., Şensoy, H., 2009. Bartın Uluyayla Yöresindeki Mera Vejetasyonunun Bazı Kantitatif Özelliklerinin Saptanması ve Ekolojik Yapının Belirlenmesi. Bartın Orman Fakültesi Dergisi, Cilt:11, Sayı:16, 81-94.

Türk, M., Bayram, G., Budaklı, E., Çelik, N., 2003. Sekonder Mera Vejetasyonun Farklı Ölçüm Metotlarının Karşılaştırılması ve Mera Durumunun Belirlenmesi. Uludağ Üniversitesi Ziraat Fakültesi Dergisi, 17(1):65-77.

Türker, A., 2006. Mersin Tarsus Oluk Koyak Köyü Topak Ardıç Mevkisinde 1997 Yılından Beri Korunmuş Ağaçlandırma Sahasındaki Otsu Vejetasyonun Özellikleri Üzerine Bir Araştırma. Yüksek Lisans Tezi, Çukurova Üniversitesi Fen Bilimleri Enstitüsü, Tarla Bitkileri Anabilim Dalı, Adana.

Uslu, Ö.S., 2005. Kahramanmaraş ili Türkoğlu İlçesi Araplar Köyü Yeni yapan Merasında Botanik Kompozisyonun Tespti ve Farklı Gübre Uygulamalarının Meranın Verim ve Botanik Kompozisyonuna Etkileri Üzerinde Araştırmalar. Doktora Tezi, Çukurova Üniversitesi Fen Bilimleri Enstitüsü, Adana.

Ünal, S., Mutlu, Z., Mermer, A., Urla, Ö., Ünal, E., Aydoğdu, M., Dedeoğlu, F., Özaydın, K.A., Avağ, A., Aydoğmuş, O., Şahin, B., Arslan, S., 2012a. Ankara ili Meralarının Değerlendirilmesi Üzerine Bir Çalışma. Tarla Bitkileri Merkez Araştırma Enstitüsü Dergisi, 21(2):41-49.

Ünal, S., Mutlu,Z., Mermer, A., Urla, Ö., Ünal, E., Özaydın, K.A., Avağ, A., Yıldız, H., Aydoğmuş, O., Şahin, B., Arslan, S., 2012b. Çankırı İli Mera Durumu ve Sağlığının Belirlenmesi Üzerine Bir Çalışma. Tarım Bilimleri Araştırma Dergisi, 5 (2): 131-135. 